\title{
Study on the Chemotherapeutic Effect and Mechanism of Doxorubicin Hydrochloride on Drug-Resistant Gastric Cancer Cell Lines Using Metal-Organic Framework Fluorescent Nanoparticles as Carriers
}

\author{
Xianmei Lv, ${ }^{1}$ Qiusheng Guo $\mathbb{D},{ }^{2}$ and Liming $\mathrm{Xu}^{1}$ \\ ${ }^{1}$ Department of Oncology, Quzhou Kecheng Hospital, Zhejiang Province, Quzhou 324000, China \\ ${ }^{2}$ The 2ND Clinical Medical College of Zhejiang Chinese Medical University, Hangzhou 310053, China \\ Correspondence should be addressed to Qiusheng Guo; zhanluzhihun@126.com
}

Received 11 October 2020; Revised 2 December 2020; Accepted 8 December 2020; Published 18 December 2020

Academic Editor: Dongyu Li

Copyright (C) 2020 Xianmei Lv et al. This is an open access article distributed under the Creative Commons Attribution License, which permits unrestricted use, distribution, and reproduction in any medium, provided the original work is properly cited.

Objective. To prepare a polyethylene glycol- (PEG-) modified rare earth metal-organic framework material drug delivery system, obtain DOX@Eu (BTC) fluorescent nanoparticles after loading doxorubicin (DOX), and explore the effect of DOX@Eu (BTC) fluorescent nanoparticles on the chemotherapy sensitivity of gastric cancer multidrug-resistant cells SGC7901/ADR. Methods. The rare earth metal-organic framework fluorescent nanoparticles EU (BTC) were prepared by the solvent method and modified with PEG, and DOX@Eu (BTC) fluorescent nanoparticles were obtained after loading DOX. The particle size distribution of the prepared nanoparticles was analyzed by TEM, the adsorption performance of the prepared nanoparticles was evaluated by BET, the effective drug loading of DOX in the nanoparticles was determined by TGA analysis, and the $\mathrm{pH}$ response release performance was evaluated by in vitro release experiments. The MTT method was used to test the toxicity of EU (BTC) to GES-1 and SGC7901/ADR cells and detect the proliferation of SGC7901/ADR cells in each group. A fluorescence confocal microscope was used to observe the positioning of DOX@Eu (BTC) in SGC7901/ADR cells. The expression level of miR-185 in each group of cells was detected by RTqPCR. The Annexin V-FITC/PI method was used to determine the apoptosis rate of cells in each group. The expression of MRS2 and related drug resistance proteins in each group of cells was detected by Western blotting (WB). The dual-luciferase reporter gene experiment was used to verify the targeting relationship between miR-185 and MRS2. Results. Most of the prepared EU (BTC) fluorescent nanoparticles have a particle size between 50 and $200 \mathrm{~nm}$ and have good adsorption capacity. The effective drug loading of DOX is $29 \%$, and it has pH-responsive release performance and can be used in acidic environments. DOX was immobilized in EU (BTC) fluorescent nanoparticles, and DOX@Eu (BTC) fluorescent nanoparticles were present in the cytoplasm or cell membrane of SGC7901/ADR cells. Compared with DOX, DOX@Eu (BTC) fluorescent nanoparticles have stronger cytotoxicity to SGC7901/ADR cells, which also effectively inhibited the expression of multidrug resistance proteins in cells. The expression level of miR-185 in SGC7901/ADR cells decreased, but the expression level of MRS2 protein in SGC7901/ADR cells increased. miR-185 and MRS2 proteins are closely related to the multidrug resistance of SGC7901/ADR cells, and MRS2 is the downstream target gene of miR-185. After the treating of SGC7901/ADR cells with DOX@Eu (BTC) fluorescent nanoparticles, the expression of miR-185 in the cells increased significantly, while the expression of MRS2 protein decreased significantly, and the magnitude of the change was more obvious than that of DOX treatment. Overexpression of miR-185 (miR-mimics) or inhibition of MRS2 (si-MRS2) enhanced the inhibitory effect of DOX@Eu (BTC) fluorescent nanoparticles on the proliferation of SGC7901/ADR cells, which significantly increased the induction of apoptosis by DOX@Eu (BTC) fluorescent nanoparticles, and simultaneous enhanced the inhibitory effect on the expression level of multidrug resistance protein. However, overexpression of miR-185 and MRS2 (pc-MRS2+miR-mimics) at the same time did not affect the chemotherapy sensitivity of SGC7901/ADR cells to DOX@Eu (BTC) fluorescent nanoparticles. However, simultaneous transfection of miR-185 mimics and pc-MRS2 did not affect the chemotherapy sensitivity of SGC7901/ADR cells to DOX@Eu (BTC) fluorescent nanoparticles. Conclusion. DOX@Eu (BTC) fluorescent nanoparticles can effectively enhance the chemotherapy sensitivity of SGC7901/ADR cells to DOX, which may be achieved by upregulating the expression of miR-185 in SGC7901/ADR cells and then inhibiting the expression of MRS2 protein. 


\section{Introduction}

Gastric cancer is a malignant tumor of the digestive tract with high morbidity and mortality worldwide [1]. Although there have been great advances in early screening and treatment of gastric cancer, the incidence of gastric cancer in my country is still high [2]. At this stage, the main treatment for gastric cancer is surgical resection, but most patients are already at an advanced stage when gastric cancer is diagnosed, and the effect of surgical treatment is still limited [3]. Studies have shown that chemotherapy has a good effect on killing tumor cells [4], but the 5-year survival period of gastric cancer patients after chemotherapy is much lower than expected [5], mainly because of the multidrug resistance of gastric cancer cells and complex tumor microenvironment $[6,7]$. The tumor microenvironment is an extremely complex system, which is the main reason for inducing drug resistance of cancer cells and affecting the efficacy of chemotherapy drugs [8]. Nanoparticles are a kind of drug delivery system proposed in recent years that can encapsulate and target chemotherapeutic drugs to tumor tissues [9], which can effectively overcome the shortcomings of free chemotherapeutic drugs in the human body such as low effective dose, poor pharmacokinetic properties, and large side effects on patients, and improve the chemotherapy effect of cancer patients. The metal-organic framework compound is a new type of hybrid material, which is famous for its porosity and has the characteristics of ultrahigh surface area and large pore size suitable for adsorbing drugs. It also has the characteristics of being degradable, and after modification, it can improve the targeting of tumor cells and is a potential chemotherapeutic drug carrier [10]. MicroRNA (miRNA) is a class of noncoding single-stranded RNA molecules whose role has always been a hot spot in cancer research. Xia et al. reported that miR-185 is closely related to the proliferation, invasion, and metastasis of pancreatic cancer cells [11]. The report of Xiang et al. showed that miR185 affects the sensitivity of ovarian cancer cells to cisplatin [12]. Also, the study by Tan et al. showed that miR-185 is related to the resistance of gastric cancer cells [13]. Doxorubicin hydrochloride (Doxorubicin, DOX) is a broad-spectrum antitumor antibiotic and a commonly used chemotherapeutic drug in the treatment of gastric cancer. However, related studies have shown that gastric cancer cells will develop resistance after exposure to DOX for a period, which affects the chemotherapy effect of DOX. [14].

This study intends to load DOX on polyethylene glycol- (PEG-) modified rare earth metal-organic framework material nanoparticles to obtain fluorescent DOX@Eu (BTC) nanoparticles and compare DOX with fluorescent DOX@Eu (BTC) nanoparticles, compare the effects of DOX and fluorescent DOX@Eu (BTC) nanoparticles on the chemotherapy sensitivity of gastric cancer multidrugresistant cell line SGC7901/ADR, and explore the mechanism of their effects on the chemotherapy sensitivity of SGC7901/ADR.

\section{Experimental Materials and Methods}

\subsection{Materials and Main Instruments}

2.1.1. Materials. Drug-resistant gastric cancer cell line SGC7901/ADR, gastric cancer cell line SGC7901, and human gastric epithelial cell line GES-1 were purchased from Shanghai Yiyan Biotechnology Co., Ltd. The primer sequences, miR-185 mimics, and si/pc-MRS2 were designed and synthesized by Biotech. Fetal bovine serum, penicillin, streptomycin, PBS buffer, pancreatin, and RPMI 1640 medium were purchased from Shanghai Yingxin Laboratory Equipment Co., Ltd. Adriamycin hydrochloride (CAS: 25316-40-9, content 99\%) was purchased from Wuhan Yuanqi Pharmaceutical Chemical Co., Ltd. Dimethylformamide (DMF), absolute ethanol, 1-(3-dimethylaminopropyl)-3-ethylcarbodiimide hydrochloride (EDC), N-hydroxysuccinimide (NHS), 1,3,5benzenetricarboxylic acid (H3BTC), europium nitrate (Eu (NO)3.6H2O), polyvinylpyrrolidone (PVP), sodium acetate ( $\mathrm{CH} 3 \mathrm{COONa} 3 \mathrm{H} 2 \mathrm{O}$ ), and dimethyl sulfoxide (DMSO) were purchased from Shanghai Anpu Experimental Technology Co., Ltd. 4',6-diamidino-2-phenylindole (DAPI), MTT cell proliferation and toxicity detection kit, Trizol kit, RT-qPCR quantitative detection kit, Annexin V-FITC/PI apoptosis detection reagent kit, WB detection kit, and dual luciferase reporter gene detection kit were purchased from Shenzhen Zike Biotechnology Co., Ltd. Human mitochondrial MRS protein (MRS2) primary antibody, multidrug resistance protein (MDR1/P-gp, MDR-1 and CST- $\pi$ ) primary antibody, GAPDH primary antibody, and corresponding secondary antibody were purchased from Santa Cruz, USA.

2.1.2. Main Instruments. Main instruments include laser confocal microscope (Zeiss LSM780), dialysis bag (Solarbio $18 \mathrm{~mm}$, molecular cutoff flow 1000), thermogravimetric analyzer (TA TGAQ50), multifunctional microplate reader (Thermo MUL TIDKAN MK3), and incubator (Thermo IGO150).

2.2. Cell Culture and Transfection. RPMI 1640 medium containing $10 \%$ fetal bovine serum, $1 \%$ penicillin, and streptomycin was used to culture drug-resistant gastric cancer cell line SGC7901/ADR, gastric cancer cell line SGC7901, and human gastric epithelial cell line GES-1, in an incubator at $37^{\circ} \mathrm{C}$, with $5 \% \mathrm{CO}_{2}$ for routine culturing. SGC7901/ADR cells were cultured with DOX at a concentration of $0.1 \mu \mathrm{g} / \mathrm{mL}$ to maintain cell resistance. SGC7901/ADR cells at the logarithmic growth phase were inoculated into a 6-well plate after $0.25 \%$ trypsin digestion, and the cell concentration was adjusted to $10^{4}$ cells/well. After overnight incubation, 50 pmol of miR-NC, miR-185 mimics, si-NC, si-MRS2, pcNC, or pc-MRS2 were transfected into SGC7901/ADR cells, respectively. After incubating the cells at $37^{\circ} \mathrm{C}$ for $4-6$ hours, the culture medium was replaced. After 24 hours, the RNA of each group was extracted, and the expression of miR-185 or MRS2 mRNA in the cells was detected by RT-qPCR.

2.3. Preparation of Nano-Eu (BTC) Loaded with Doxorubicin Hydrochloride. A certain amount of $\mathrm{H}_{3} \mathrm{BTC}$, Eu (NO) $)_{3} \cdot 6 \mathrm{H}_{2} \mathrm{O}, \mathrm{PVP}$, and $\mathrm{CH}_{3} \mathrm{COONa} \cdot 3 \mathrm{H}_{2} \mathrm{O}$ according to the 
ratio of $1: 2: 47: 20$ was weighted. $\mathrm{H}_{3} \mathrm{BTC}$ and $\mathrm{Eu}(\mathrm{NO})_{3} \cdot 6 \mathrm{H}_{2} \mathrm{O}$ were dissolved in DMF to obtain the reaction precursor; PVP and $\mathrm{CH}_{3} \mathrm{COONa} \cdot 3 \mathrm{H}_{2} \mathrm{O}$ were dissolved in the mixed solvent in advance (MDF : $\mathrm{C}_{2} \mathrm{H}_{6} \mathrm{O}: \mathrm{H}_{2} \mathrm{O}=3: 2: 2$ ). After that, the reaction precursor and the mixed solvent were transferred to a round-bottomed flask and mixed well to obtain the reaction solution. Heat the oil bath to $80^{\circ} \mathrm{C}$ and stir; after $24 \mathrm{~h}$, absolute ethanol was used to wash 3 times to obtain Eu (BTC) crystals. $5 \mathrm{mg}$ of dried Eu (BTC) crystals were dispersed in $7 \mathrm{~mL}$ of $\mathrm{H}_{2} \mathrm{O}$ and stirred at room temperature. $10 \mathrm{mg}$ EDC, $10 \mathrm{mg}$ NHS, and $20 \mathrm{mg}$ PEG were dissolved in $1 \mathrm{~mL} \mathrm{H}_{2} \mathrm{O}$, and the EDC solution was added to the stirred $\mathrm{Eu}$ (BTC) dispersion and continued to stir for 10 minutes before adding the NHS solution. The reaction was continued at room temperature for $24 \mathrm{~h}$ and centrifuged $(500 \times \mathrm{g})$ for $5 \mathrm{~min}$. The precipitated PEG-modified fluorescent Eu (BTC) nanoparticles were collected and washed. $5 \mathrm{mg}$ of dried fluorescent Eu (BTC) nanoparticle powder was used and immersed in $1 \mathrm{~mL}$ DOX aqueous solution $(8 \mathrm{mg} / \mathrm{mL})$ and stirred for $24 \mathrm{~h}$ at room temperature to obtain DOXloaded fluorescent Eu (BTC) nanoparticle (DOX@Eu (BTC)).

\subsection{Identification of Fluorescent DOX@Eu (BTC)} Nanoparticles. An appropriate amount of PEG-modified fluorescent Eu (BTC) nanoparticles was dissolved in $\mathrm{H}_{2} \mathrm{O}$. After stirring, a transmission electron microscope was used to take pictures of different positions, the particle diameters of 500 nanoparticles in different positions were counted, and a particle size distribution map was made. Take an appropriate amount of PEG-modified fluorescent Eu (BTC) nanoparticles for washing and dry at $170^{\circ} \mathrm{C}$ to obtain a white powder. After setting the specific surface tester parameters, its nitrogen adsorption-desorption isotherm was tested under the condition of the ice-water mixture. The thermal stability of fluorescent Eu (BTC) nanoparticles and fluorescent DOX@Eu (BTC) nanoparticles and the effective DOX load of fluorescent DOX@Eu (BTC) nanoparticles were analyzed with a thermogravimetric analyzer. $5 \mathrm{mg}$ of the sample to be tested was placed on the tray, and the speed was measured under an $\mathrm{N}_{2}$ atmosphere; the heating rate is $20^{\circ} \mathrm{C} / \mathrm{min}$, and the maximum temperature is $900^{\circ} \mathrm{C}$. The dialysis method was used to compare the DOX release of fluorescent DOX@Eu (BTC) nanoparticles in vitro at different pHs. An appropriate amount of fluorescent DOX@Eu (BTC) nanoparticles was dissolved in $\mathrm{H}_{2} \mathrm{O}$, centrifuged $(500 \times \mathrm{g})$ for $5 \mathrm{~min}$, and then removed clear. After washing 3 times with ultrapure water, the precipitate was resuspended in $3 \mathrm{~mL}$ of the corresponding $\mathrm{pH}$ buffer solution, and after mixing, transferred to a dialysis bag and placed in the same $\mathrm{pH}$ buffer solution. Finally, stir at a speed of $300 \mathrm{rpm}$, and the amount of DOX released at each time point was recorded.

\subsection{Fluorescent Eu (BTC) Nanoparticle Toxicity Test (MTT).} An appropriate amount of fluorescent Eu (BTC) nanoparticles was dissolved in PBS buffer; the density was adjusted to $2 \mathrm{mg} / \mathrm{mL}$. SGC7901/ADR cells were inoculated at a density of $10^{4}$ cells/well in a 96-well plate and incubated overnight. The prepared fluorescent Eu (BTC) nanoparticle solution was diluted; the final concentration was adjusted to $20 \mu \mathrm{g} / \mathrm{mL}, 10 \mu \mathrm{g} / \mathrm{mL}, 4 \mu \mathrm{g} / \mathrm{mL}, 1 \mu \mathrm{g} / \mathrm{mL}$, and $0.1 \mu \mathrm{g} / \mathrm{mL}$; and a blank control was also set. The medium in the 96-well plate was aspirated, and $200 \mu \mathrm{L}$ of each gradient concentration solution was added, incubated for $24 \mathrm{~h}$ after adding the drug. Then, $20 \mu \mathrm{L}$ of MTT $(5 \mu \mathrm{g} / \mathrm{mL})$ solution was added to each well and incubated for $4 \mathrm{~h}$. After aspirating the test solution in each well, $150 \mu \mathrm{L}$ DMSO was added to dissolve the crystals. Finally, a multifunctional microplate reader was used to detect the absorbance of each group of cells at $490 \mathrm{~nm}$, and the absorbance was recorded.

2.6. Sensitivity of SGC7901/ADR Cells to DOX and Fluorescent DOX@Eu (BTC) (MTT). An appropriate amount of DOX or fluorescent DOX@Eu (BTC) nanoparticles was dissolved in PBS buffer to ensure that the net DOX concentration is $10 \mu \mathrm{g} / \mathrm{mL}$, and a blank control was also set. The MTT method was used to detect the effects of DOX and fluorescent DOX@Eu (BTC) nanoparticles on the cell viability of each group of SGC7901/ADR. The method was the same as the above, and the absorbance of each group of cells at $1 \mathrm{~h}$, $6 \mathrm{~h}, 12 \mathrm{~h}, 24 \mathrm{~h}, 36 \mathrm{~h}, 48 \mathrm{~h}, 60 \mathrm{~h}$, and $72 \mathrm{~h}$ was recorded.

2.7. Observation of the Fluorescent DOX@Eu (BTC) Localization in Cell by a Confocal Laser Microscope. An appropriate amount of fluorescent DOX@Eu (BTC) nanoparticles was dissolved in PBS buffer to ensure that the net DOX concentration is $10 \mu \mathrm{g} / \mathrm{mL}$. The prepared PBS solution was cocultured with SGC7901/ADR cells for $12 \mathrm{~h}$. After incubation, the nuclei were stained with DAPI, and the localization of fluorescent DOX@Eu (BTC) nanoparticles in the cells was observed by a laser confocal microscope.

2.8. Detection of the Expression of miR-185 and MRS2 $m R N A$ in Cells. Trizol one-step method was used to extract total RNA from each group of cells, and $2 \mu \mathrm{g}$ total RNA was used to synthesize cDNA. Take $2 \mu \mathrm{L}$ of reverse transcription product, $10 \mu \mathrm{L}$ of SYBR Green Mix, $0.5 \mu \mathrm{L}$ of the upstream, and downstream primers of miR-185 or MRS2 mRNA and establish a PCR reaction system with a total volume of $20 \mu \mathrm{L}$ according to the kit instructions. The PCR thermal cycle parameters were $95^{\circ} \mathrm{C}$ for $5 \mathrm{~min}, 94^{\circ} \mathrm{C}$ for $30 \mathrm{~s}$, and $60^{\circ} \mathrm{C}$ for $30 \mathrm{~s}$, with a total of 45 cycles. The primer sequence is as follows: MRS2(R): $5^{\prime}$-CCAGAACCATGGAATGCCTGC-3', ${ }^{\prime}, \quad \operatorname{MRS} 2(\mathrm{~F}): \quad 5^{\prime}$ -GTATCCACGGGGCTGTTCCTAAC-3'; miR-185(R): $5^{\prime}$ -CAATGGAGAGAAAGGCAGTTCC-3', miR-185(F): $5^{\prime}$ -AATCCATGAGAGATCCCTACCG-3'; GAPDH(R): $5^{\prime}$ -CGCTCCTGGAAGATGGTGAT-3', GAPDH(F): $5^{\prime}$-GACC CCTTTCATTGACCTCAAC- $3^{\prime}$. The $2^{(-\triangle \triangle \mathrm{Ct})}$ method was used to calculate the relative expression level of each gene.

2.9. Detection of Apoptosis Level. The cells in each group were cultured for 24 hours, and DOX or fluorescent DOX@Eu (BTC) nanoparticle solution with a net concentration of $10 \mu \mathrm{g} / \mathrm{mL}$ was added. After continuing the routine culture for 48 hours, the cells were digested with $0.25 \%$ trypsin and collected. After washing 3 times with PBS, the apoptosis ratio of each group was determined by Annexin V-FITC/PI double staining according to the kit instructions.

2.10. Detection of the Protein Expression of Multidrug Resistance Gene and MRS2. Cells at the logarithmic growth 
phase were collected to extract the total protein in each group of cells, and the protein concentration was determined by the BCA method. After adding SDS-PAGE loading buffer, heat denaturation treatment was performed. $15 \mu \mathrm{g}$ total protein was added to each lane, and electrophoresis with $20 \mathrm{~mA}$ current for $60 \mathrm{~min}$. The sample was transferred to the PVDF membrane by the wet transfer method and sealed with 5\% skim milk at room temperature for 3 hours. After that, the diluted multidrug resistance protein primary antibody, MRS2 primary antibody, or GAPDH primary antibody $(1: 1000)$ was added and incubated overnight at $4^{\circ} \mathrm{C}$. Then, the corresponding secondary antibody $(1: 10000)$ was added and incubated at room temperature for $1 \mathrm{~h}$. Finally, after ECL luminescence development, pictures were taken, and Image-j was used to analyze the gray value of each band, and the relative expression level was calculated.

2.11. The Verification of the Targeting Relationship between miR-185 and MRS2 by Dual-Luciferase Reporter Gene Experiment. Cells at the logarithmic growth phase were collected, digested with $0.25 \%$ trypsin, and inoculated in a 96well plate at a density of $10^{4}$ cells/well. After overnight incubation, miR-NC, WT-MRS2 or MUT-MRS2, miR-185 mimics, and WT-MRS2 or MUT-MRS2 were transfected into SGC7901/ADR cells and then incubated for $48 \mathrm{~h}$ after transfection. The cell suspension in each well was centrifuged $(1000 \times \mathrm{g})$ for 5 minutes, and the supernatant was collected and transferred to a 96-well plate. The fluorescence of each well was measured when the firefly luciferase substrate and the Renilla luciferase substrate were added. The relative luciferase activity was calculated of each well.

2.12. Statistical Analysis. All experiments are repeated three times, and the data were expressed as mean \pm standard deviation $(\bar{x} \pm s)$. GraphPad Prism 8.2.1 software was used for data analysis and picture drawing. The comparison between the two groups was performed by $t$ test, and the comparison between multiple groups was performed by one-way analysis of variance. $P<0.05$ or $P<0.01$ indicated that the difference was statistically significant.

\section{Results}

3.1. Characterization of Fluorescent DOX@Eu (BTC) Nanoparticles. The particle size of PEG-modified fluorescent $\mathrm{Eu}$ (BTC) nanoparticles was analyzed, and the results showed that the average particle size was $130 \mathrm{~nm}$, the maximum was $270 \mathrm{~nm}$, and the minimum was $60 \mathrm{~nm}$. More than $74 \%$ of the nanoparticles have a size distribution between 100 and $200 \mathrm{~nm}$ (see Figure 1(a)). The micropore structure of the prepared fluorescent Eu (BTC) nanoparticles was characterized, and the results showed that the specific surface area of the PEG-modified fluorescent Eu (BTC) nanoparticles was $2461.11 \mathrm{~m}^{2} / \mathrm{g}$, and the pore volume was $0.76 \times 10^{-6} \mathrm{~m}^{3} / \mathrm{g}$. The average pore radius is $38.29 \times 10^{-10} \mathrm{~m}$, and the $\mathrm{N}_{2}$ adsorption-desorption isotherm has obvious hysteresis loops, which is a characteristic curve of typical mesoporous materials and has good adsorption capacity (as shown in Figure 1(b)). After loading DOX, fluorescent DOX@Eu
(BTC) nanoparticles were obtained, and the heating curves of fluorescent $\mathrm{Eu}$ (BTC) nanoparticles and fluorescent DOX@Eu (BTC) nanoparticles were compared. The quality of fluorescent Eu (BTC) nanoparticles decreased steadily at $20 \sim 350^{\circ} \mathrm{C}$, and the rate of mass decrease appears a short plateau at $350^{\circ} \mathrm{C}$. The mass loss caused by bound water and DMF was about $20 \%$, which was consistent with the theoretical calculation. For fluorescent DOX@Eu (BTC) nanoparticles, the temperature rise curve was similar to fluorescent $\mathrm{Eu}$ (BTC) nanoparticles below $200^{\circ} \mathrm{C}$. When the temperature was above $200^{\circ} \mathrm{C}$, DOX gradually decomposed, increasing the rate of mass decline. At $350^{\circ} \mathrm{C}$, the remaining mass percentage of fluorescent DOX@Eu (BTC) nanoparticles was about $71 \%$, that is, the effective drug loading of fluorescent DOX@Eu (BTC) nanoparticles was about 29\%. The remaining mass percentages of fluorescent Eu (BTC) nanoparticles and fluorescent DOX@Eu (BTC) nanoparticles at $900^{\circ} \mathrm{C}$ were $29.53 \%$ and $40.12 \%$, which were consistent with the theoretical calculation values (as shown in Figure 1(c)). The in vitro release of fluorescent DOX@Eu (BTC) nanoparticles at different pHs was compared, and the results showed that when the $\mathrm{pH}$ was 7.4, the release of DOX was relatively slow, and the release rate gradually increased as the $\mathrm{pH}$ decreased (as shown in Figure 1(d)).

3.2. The Effect of Fluorescent DOX@Eu (BTC) on SGC7901/ADR Cells. MTT was used to detect the toxicity of fluorescent Eu (BTC) to GES-1 and SGC7901/ADR cells. The results showed that the concentration of fluorescent Eu (BTC) at $0.1 \sim 20 \mu \mathrm{g} / \mathrm{mL}$ had no significant effect on cell survival, indicating that fluorescent Eu (BTC) was nontoxic to GES-1 and SGC7901/ADR cells (as shown in Figure 2(a)). The laser confocal microscope was used to observe the positioning of fluorescent DOX@Eu (BTC) in the cell, and the results showed that the red fluorescence did not overlap with the blue fluorescence, and the red fluorescence was ringed around the blue fluorescence, indicating that DOX was fixed on the fluorescent Eu (BTC) nanoparticles and cannot enter the nucleus. DOX and Eu (BTC) existed together in the cell membrane or cytoplasm (as shown in Figure 2(b)). MTT method was also used to detect the inhibitory effect of DOX and fluorescent DOX@Eu (BTC) on SGC7901/ADR cells. With the increase of the action time under the same net DOX concentration, both DOX and fluorescent DOX@Eu (BTC) can significantly reduce the SGC7901/ADR cell survival rate $(P<0.05)$. In the first $30 \mathrm{~h}, \mathrm{DOX}$ inhibited cells better than fluorescent DOX@Eu (BTC) nanoparticles, but after 30 h, fluorescent DOX@Eu (BTC) inhibited cells better than DOX. This was caused by the gradual release of DOX loaded in fluorescent Eu (BTC) and the gradual increase in the effective drug concentration in the cells (as shown in Figure 2(c)). Annexin V-FITC/PI was performed to detect the effects of DOX and fluorescent DOX@Eu (BTC) on SGC7901/ADR cell apoptosis. The results showed that both DOX and fluorescent DOX@Eu (BTC) significantly increased the early apoptosis and late apoptosis of SGC7901/ADR cells $(P<0.05)$, and fluorescent DOX@Eu (BTC) had a more obvious effect on the early apoptosis of SGC7901/ADR cell $(P<0.05)$ (see Figure $2(\mathrm{~d}))$. Western blotting was used to 


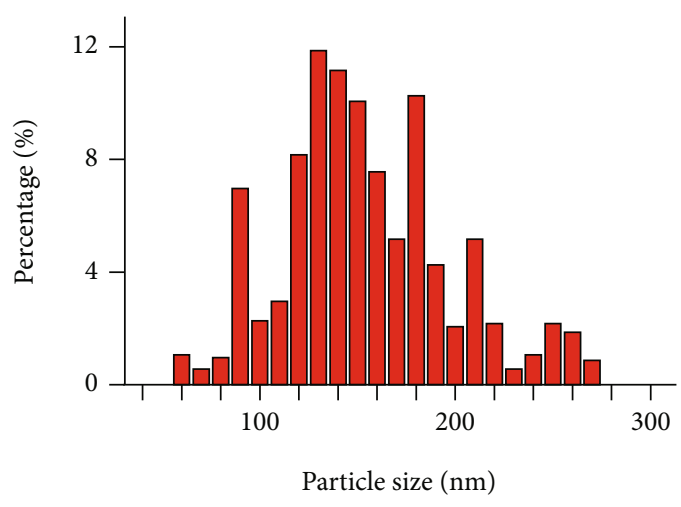

(a)

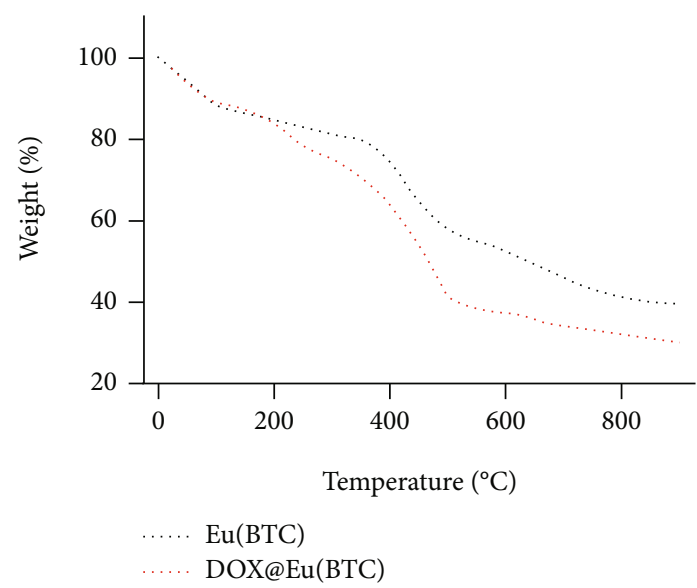

(c)

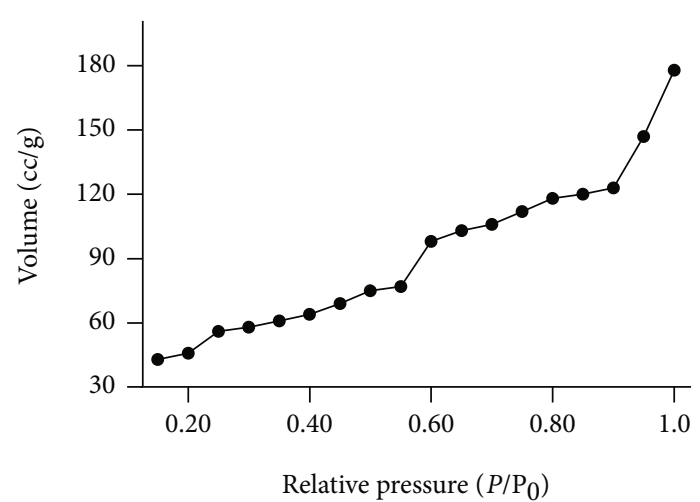

(b)

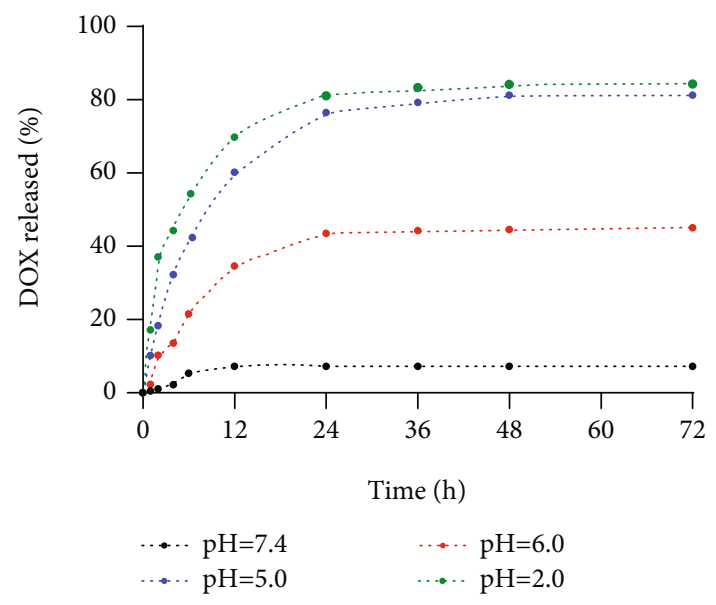

(d)

FIGURE 1: Characterization of prepared fluorescent nanoparticles. (a) Size distribution of nano-Eu (BTC). (b) Nitrogen adsorption-desorption isotherm curve of nano-Eu (BTC); (c) TGA analysis of Eu (BTC) and DOX@Eu (BTC). (c) TGA analysis of DOX@Eu (BTC) and Eu (BTC). (d) Releasing the curve of the DOX in vitro under different $\mathrm{pH}$.

detect the expression of resistance-related proteins, and the results showed that both DOX and fluorescent DOX@Eu (BTC) significantly inhibited the expression of MDR1/P-gp, MDR-1, and CST- $\pi$ proteins in cells $(P<0.05)$, and fluorescent DOX@Eu (BTC) has a more obvious inhibitory effect on the expression of multidrug resistance protein $(P<0.05)$ (see Figure 2(e)).

3.3. The Effect of miR-185 on the Drug Resistance of SGC7901/ADR Cells. RT-qPCR was used to detect the expression of miR-185 in different cell lines. The results showed that the expression of miR-185 in SGC7901 and SGC7901/ADR cell lines was significantly lower than that in GES-1 cell line $(P<0.05)$, and the expression level in SGC7901/ADR cell line was the lowest $(P<0.05)$ (see Figure 3(a)). When miR-185 mimics were transfected into the SGC7901/ADR cell line, the expression level of miR-185 in the cells increased significantly $(P<0.05)$ (as shown in Figure 3(b)). MTT was used to detect the toxicity of fluorescent DOX@Eu (BTC) to SGC7901/ADR cells transfected with miR-185 mimics. The results showed that the transfection of miR-185 mimics can significantly enhance the toxicity of fluorescent DOX@Eu (BTC) to SGC7901/ADR cells and inhibit the proliferation of SGC7901/ADR cells $(P<0.05)$ (as shown in Figure 3(c)). Annexin V-FITC/PI was used to detecting the effect of fluorescent DOX@Eu (BTC) on the apoptosis of SGC7901/ADR cells transfected with miR-185 mimics. The results showed that the transfection of miR185 mimics significantly increased the apoptosis of SGC7901/ADR cells induced by fluorescent DOX@Eu (BTC) $(P<0.05)$, which had a more obvious effect on the early apoptosis of SGC7901/ADR cells $(P<0.05)$ (as shown in Figure 3(d)). Western blotting was used to detect the effect of fluorescent DOX@Eu (BTC) on the expression of related drug resistance proteins in SGC7901/ADR cells transfected with miR-185 mimics. The results showed that transfection of miR-185 mimics significantly enhanced the inhibitory effect of fluorescent DOX@Eu (BTC) on the expression of related drug-resistant proteins $(P<0.05)$ (as shown in Figure 3(e)).

3.4. Targeting Relationship between miR-185 and MRS2. The bioinformatics website ENCORI predicted potential downstream target genes of miR-185. The results showed that MRS2 was a downstream target gene of miR-185, and the target binding sequence was shown in Figure 4(a). The dualluciferase reporter gene experiment verified the targeting relationship between miR-185 and MRS2. The results 


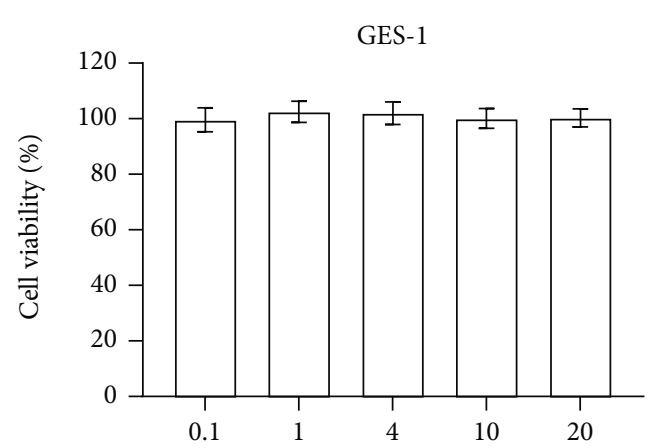

Concentration of $\mathrm{Eu}(\mathrm{BTC}) /(\mu \mathrm{g} / \mathrm{mL})$

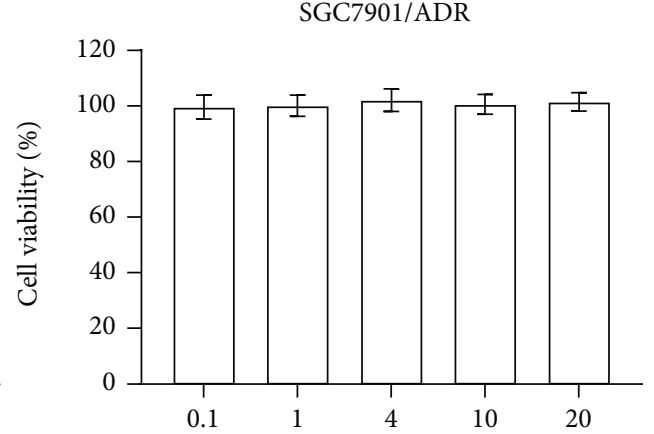

Concentration of $\mathrm{Eu}(\mathrm{BTC}) /(\mu \mathrm{g} / \mathrm{mL})$

(a)

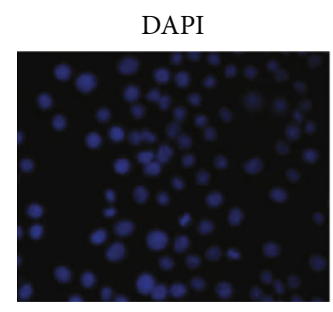

DOX@Eu(BTC)
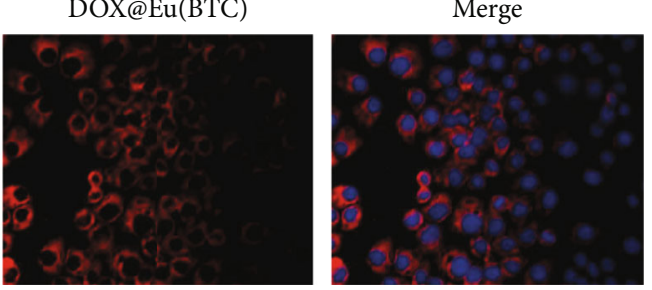

(b)

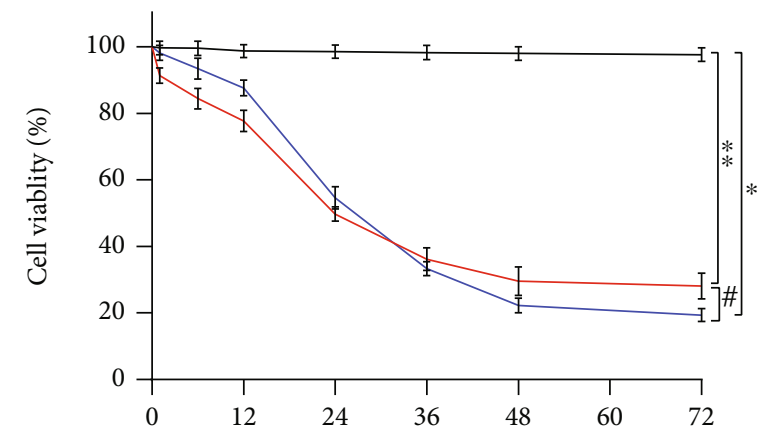

Time (h)

- NC

DOX

—_DOX@Eu(BTC)

(c)
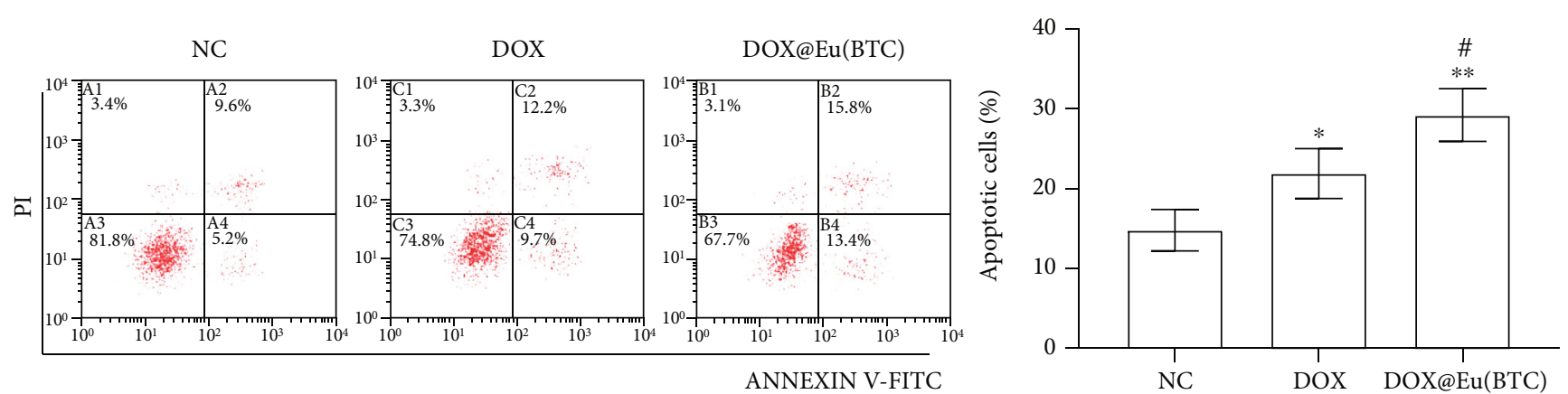

(d)

Figure 2: Continued. 

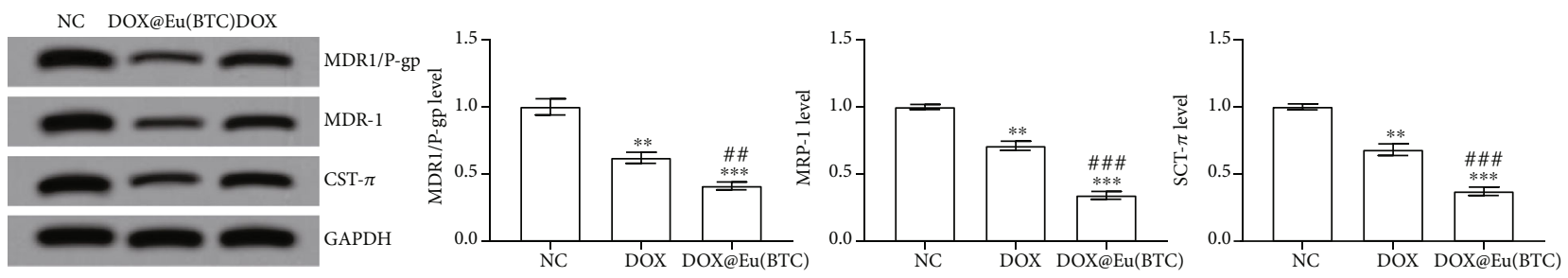

(e)

Figure 2: Effect of DOx@EU (BTC) fluorescent nanoparticles on SGC7901/ADR cells. (a) Result of the cytotoxic test of Eu (BTC). (b) CLSM image of SGC7901/ADR cells after incubation with DOX@Eu (BTC). (c) Result of the cytotoxic test of DOX and DOX@Eu (BTC) after different incubation times. (d) Result of DOX and DOX@EU (BTC) on the apoptosis rate of SGC7901/ADR cells. (e) Result of DOX and DOX@EU (BTC) on multidrug resistance protein relative expression level of SGC7901/ADR cells.

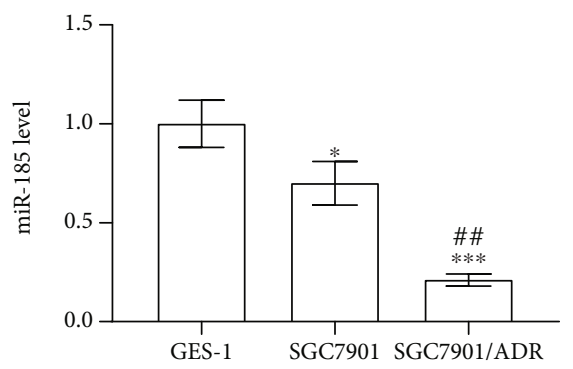

(a)

NC

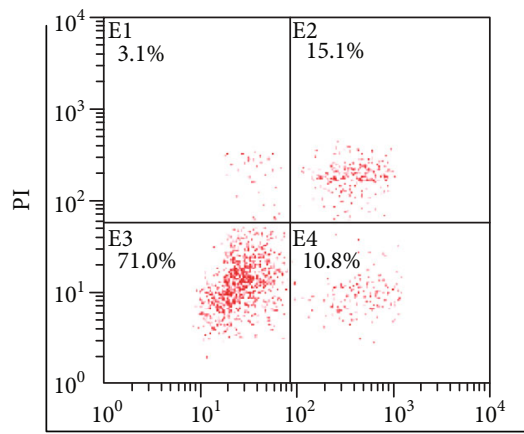

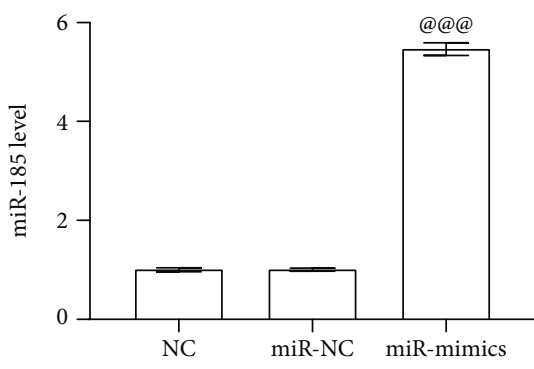

(b)

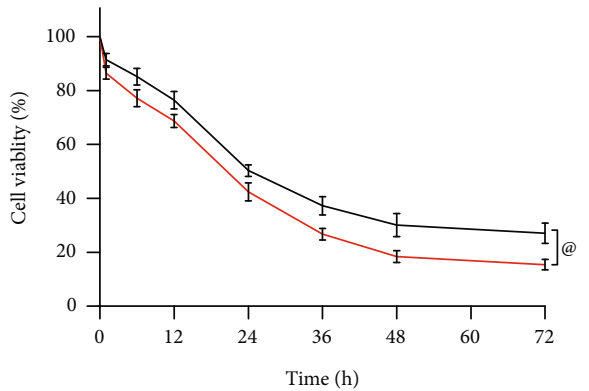

$-\mathrm{NC}$

- miR-mimics

miR-mimics
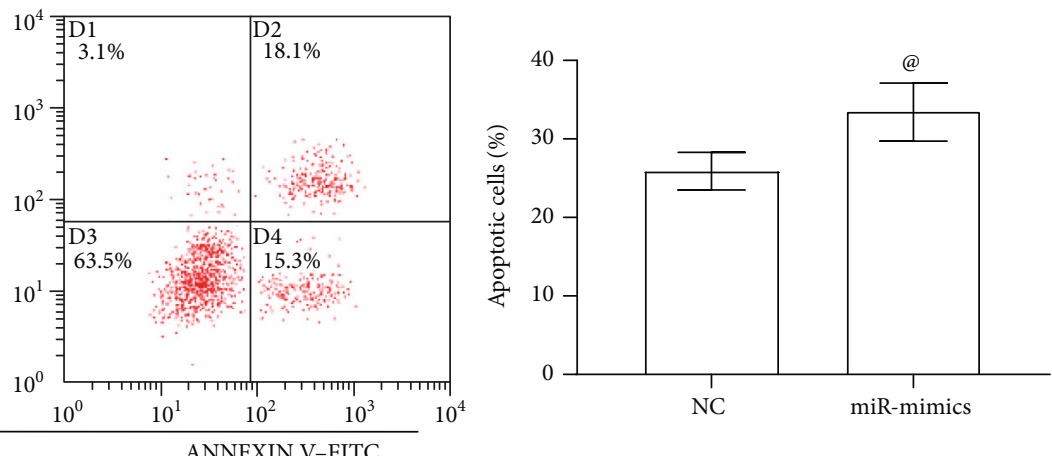

(d)
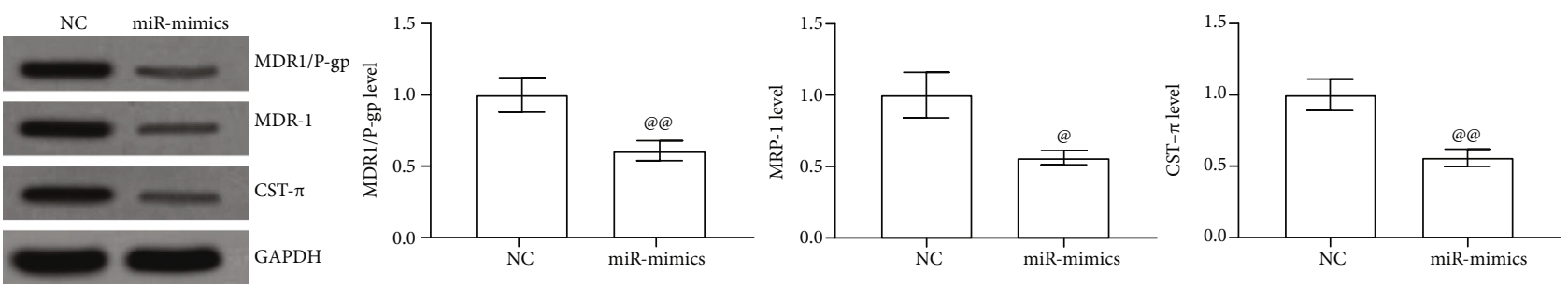

(e)

Figure 3: Effect of miR-185 on the drug resistance of SGC7901/ADR cells. ${ }^{*} P<0.05$ and ${ }^{* * *} P<0.001$ vs. GES-1 group; ${ }^{\# \#} P<0.01$ vs. SGC7901 group; ${ }^{@} P<0.05$, ${ }^{@} P<0.01$, and ${ }^{@ @ @ ~} P<0.001$ vs. NC group. (a, b) The expression level of miR-185 in SGC7901/ADR cells. (c) Comparison of DOX@Eu (BTC) on cell viability SGC7901/ADR cell by different transfection. (d) Comparison of DOX@Eu (BTC) on cell apoptosis rate SGC7901/ADR cell by different transfection. (e) Comparison of DOX@Eu (BTC) on multidrug resistance protein relative expression SGC7901/ADR cell by different transfection. 
MSR2: $5^{\prime}$-cgauuGGCUGACGAUCUCUCCa-3'

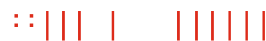

miRNA: 5 '-aguccUUGACGGAAAGAGAGGu-3'

(a)

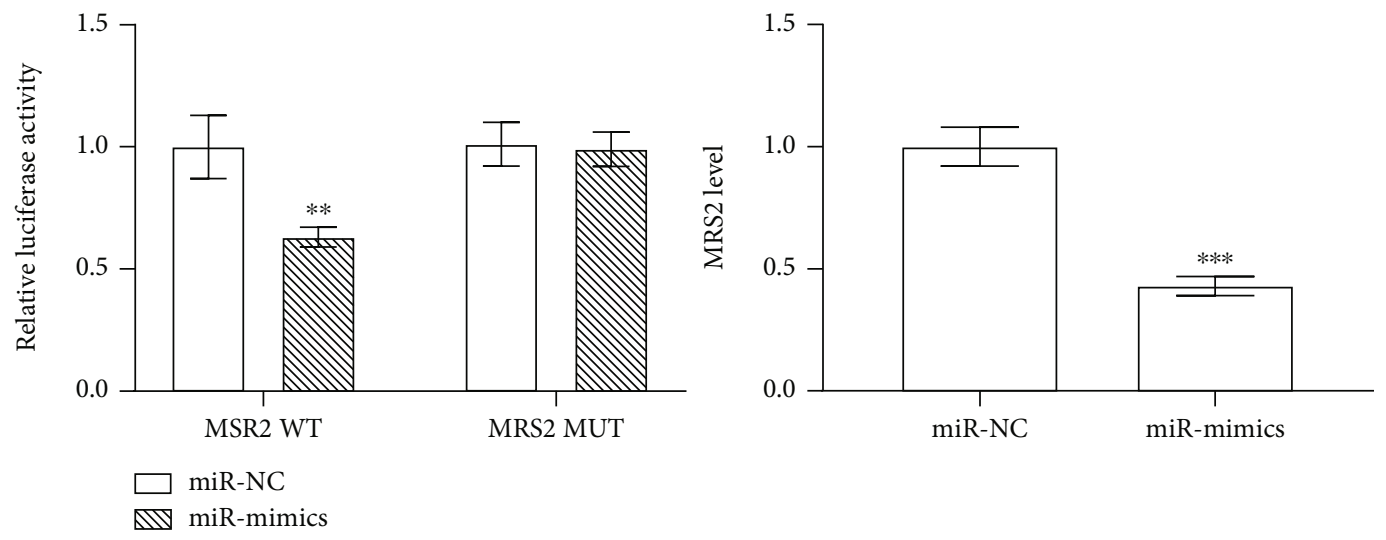

(b)

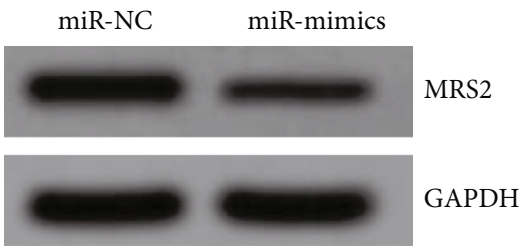

(c)

FIGURE 4: Verification of the targeting relationship between miR-185 and MRS2. ${ }^{* *} P<0.01$ and ${ }^{* * *} P<0.001$ vs. miR-NC group. (a) Targeting area of miR-185 and MRS2. (b) Dual-luciferase reporter gene verified the targeting relationship between miR-185 and MRS2. (c) Expression levels of MRS2 in SGC7901/ADR cell.

showed that miR-185 significantly inhibited the luciferase activity of the wild-type MRS2 vector $(P<0.05)$ (as shown in Figure 4(b)). Western blotting was used to detect the effect of miR-185 on the expression level of MRS2 protein, and the results demonstrated that miR-185 significantly inhibited the expression level of MRS2 protein (as shown in Figure 4(c)).

3.5. The Effect of MRS2 on the Drug Resistance of SGC7901/ADR Cells. Western blotting was used to detect the expression of MRS2 in different cell lines and SGC7901/ADR cells after transfection with si-MRS2. The results showed that the expression of MRS2 protein in SGC7901 and SGC7901/ADR cell lines was significantly higher than that in GES-1 cells $(P<0.05)$, and the expression level in SGC7901/ADR cell line was the highest $(P<0.05)$ (see Figure 5(a)). SGC7901/ADR cell line was transfected with siMRS2, and the expression level of MRS2 protein in the cells was significantly reduced $(P<0.05)$ (as shown in Figure 5(b)). MTT was used to detect the toxicity of fluorescent DOX@Eu (BTC) to SGC7901/ADR cells transfected with si-MRS2, and the results discovered that the transfection of siMRS2 can significantly inhibit the proliferation of SGC7901/ADR cells $(P<0.05)$ (as shown in Figure 5(c)). Annexin V-FITC/PI was used to detecting the effect of fluorescent DOX@Eu (BTC) on the apoptosis of SGC7901/ADR cells transfected with si-MRS2. The results showed that the transfection of si-MRS2 significantly increased the apoptosis of
SGC7901/ADR cells induced by fluorescent DOX@Eu (BTC) $(P<0.05)$, which had similar effects on early and late apoptosis of SGC7901/ADR cells (as shown in Figure 5(d)). Western blotting was used to detect the effect of fluorescent DOX@Eu (BTC) on the expression of related drug resistance proteins in SGC7901/ADR cells transfected with si-MRS2. The results showed that the transfection of si-MRS2 significantly inhibited the expression of related drug resistance proteins in the SGC7901/ADR cell line $(P<0.05)$ (as shown in Figure 5(e)).

3.6. Fluorescent DOX@Eu (BTC) Affects the Chemotherapy Sensitivity of SGC7901/ADR Cells through the miR185/MRS2 Molecular Axis. RT-qPCR was used to detect the expression of miR-185 in SGC7901/ADR cells after treatment with DOX and fluorescent DOX@Eu (BTC). The results showed that the expression of miR-185 in SGC7901/ADR cells was significantly increased after drug treatment $(P<0.05)$, and the expression of miR-185 after fluorescent DOX@Eu (BTC) treatment was significantly higher than that after DOX treatment $(P<0.05)$ (see Figure 6(a)). Western blotting was used to detect the expression level of MRS2 in SGC7901/ADR cells after treatment. The results showed that the expression level of MRS2 protein in SGC7901/ADR cells was significantly reduced after drug treatment, and the expression level of MRS2 protein after fluorescent DOX@Eu (BTC) treatment was significantly lower than that after DOX treatment $(P<0.05)$ (see 


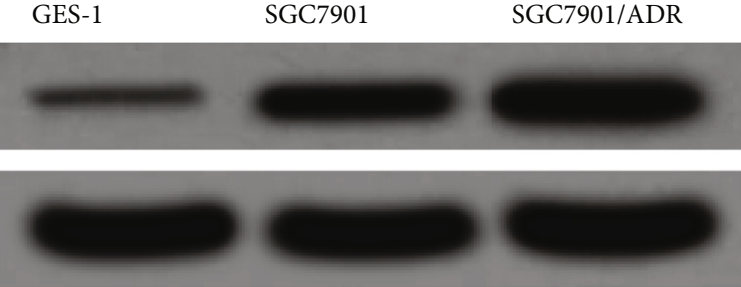

GAPDH

MRS2
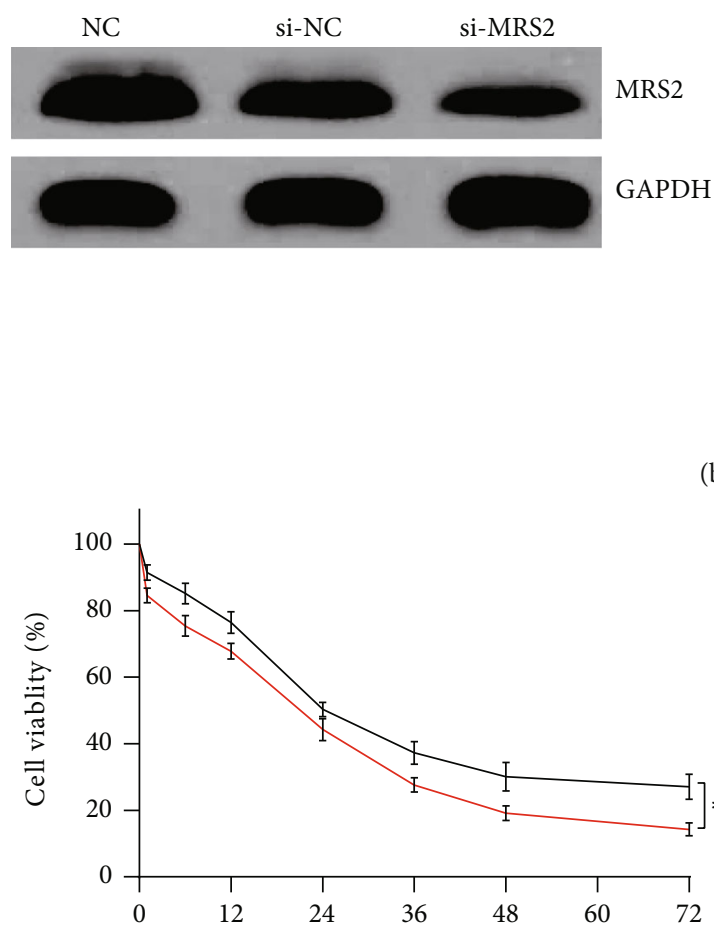

Time (h)

NC

— si-MRS2

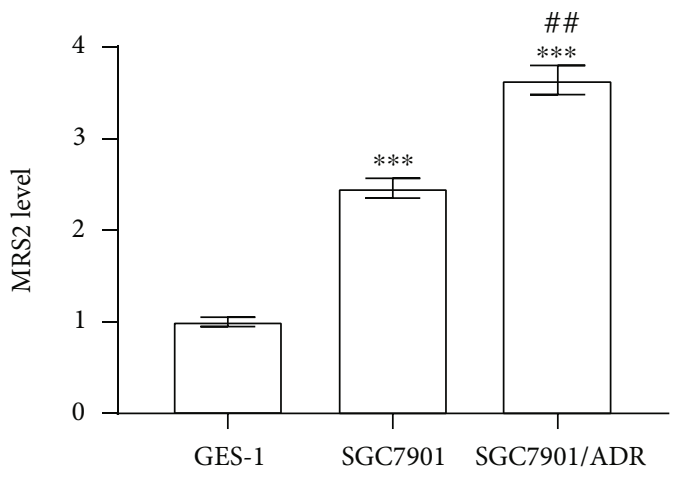

(a)

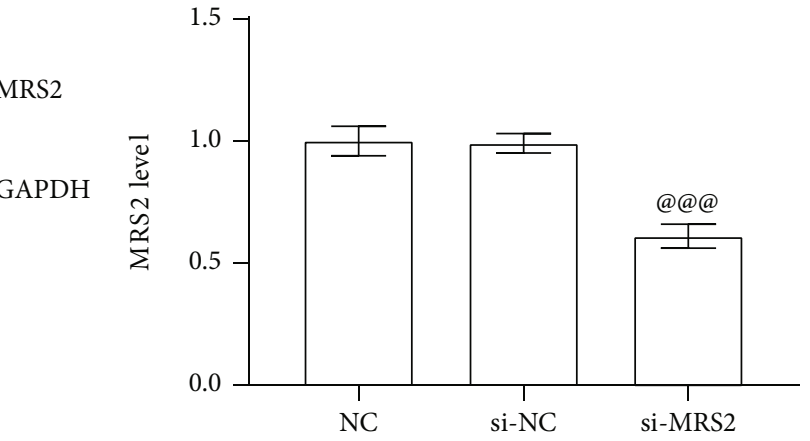

(b)

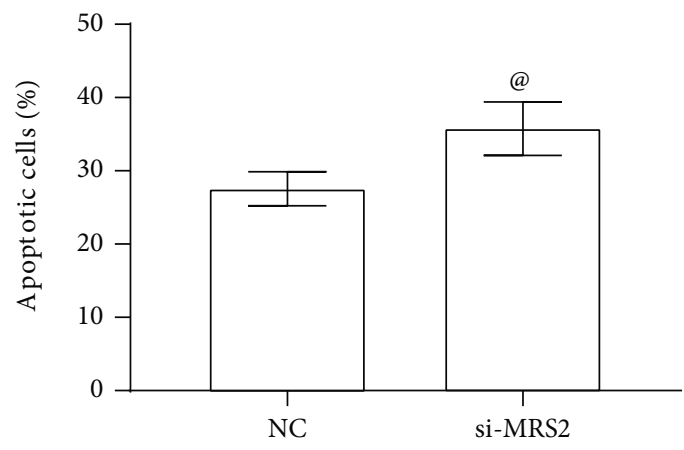

(c)

FIgure 5: Continued. 
NC

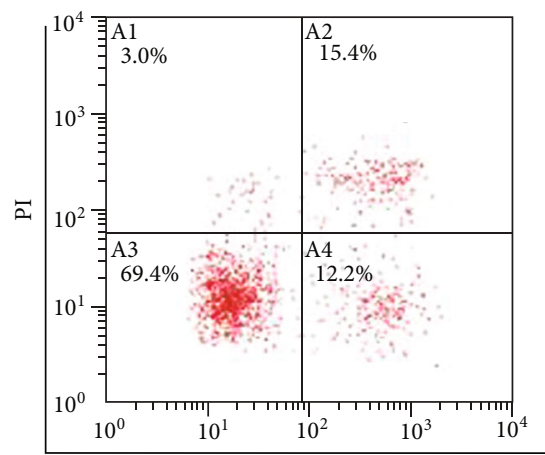

si-MRS2

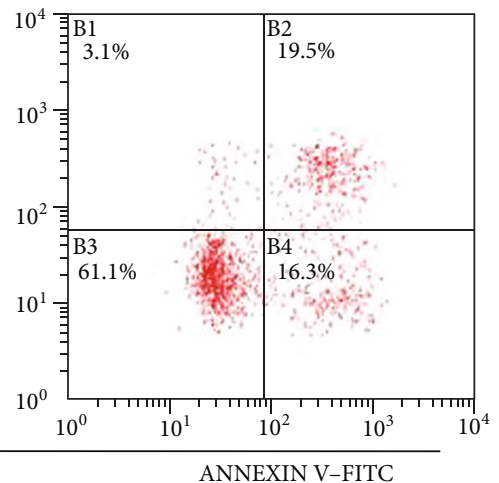

(d)
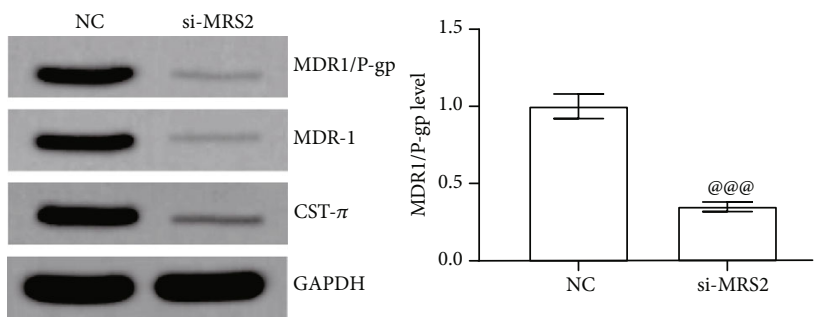
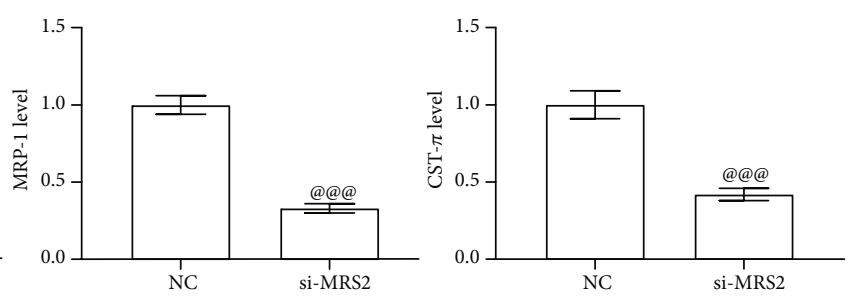

(e)

FIGURE 5: Effect of MRS2 on the drug resistance of SGC7901/ADR cells. ${ }^{* * *} P<0.001$ vs. GES-1 group; ${ }^{\# \#} P<0.01$ vs. SGC7901 group; ${ }^{\circledR} P<0.05$ and ${ }^{@ @} P<0.001$ vs. NC group. $(\mathrm{a}, \mathrm{b})$ The expression level of MRS2 in SGC7901/ADR cells. (c) Comparison of DOX@Eu (BTC) on cell viability SGC7901/ADR cell by different transfection. (d) Comparison of DOX@Eu (BTC) on cell apoptosis rate SGC7901/ADR cell by different transfection. (e) Comparison of DOX@Eu (BTC) on multidrug resistance protein relative expression SGC7901/ADR cell by different transfection.

Figure 6(b)). After the transfection of pc-MRS2, the expression level of MRS2 protein in SGC7901/ADR cells increased significantly $(P<0.05)$; however, transfection of miR-185 mimics and pc-MRS2 at the same time had no significant effect on the expression level of MRS2 protein in SGC7901/ADR cells (as shown in Figure 6(c)). MTT, Annexin V-FITC/PI, and Western blotting were used to detect the effects of fluorescent DOX@Eu (BTC) on the proliferation, apoptosis, and related drug resistance protein expression of SGC7901/ADR cells transfected with miR-185 mimics and pc-MRS2. The results showed that the expression levels of proliferation, apoptosis, and related drug resistance proteins in fluorescent DOX@Eu (BTC) treatment of SGC7901/ADR cells transfected with miR-185 mimics and pc-MRS2 at the same time were not significantly different from those of untransfected SGC7901/ADR cells (see Figures 6(d)-6(f)).

\section{Discussion}

Gastric cancer ranks first among the malignant tumors of the digestive tract in my country, with a poor prognosis [1]. Chemotherapy is the main method for the treatment of advanced gastric cancer. However, the emergence of multidrug resistance in gastric cancer cells often leads to chemotherapy failure. Studies have shown that drug delivery systems using nanoparticles as carriers can target drugs to tumor tissues and improve the sensitivity of tumor tissues to chemotherapy
[15]. Nanodrug carrier refers to a drug delivery system obtained by combining nanoparticles with a particle size of $10 \sim 1000 \mathrm{~nm}$ and drugs, which can transport drugs to tumor tissues, change the distribution of drugs in patients, and reduce the loss of drugs in the normal group, which can also reduce side effects and improve the bioavailability of drugs. Compared with general materials, metal-organic framework materials have the characteristics of larger specific surface area and porosity. It is currently known as the largest and lightest crystalline material with the largest specific surface area. In recent years, it has achieved rapid development in the field of drug release [16]. Because rare-earth metal-organic framework materials integrate the advantages of metal-organic framework materials as nano-drug carriers and the excellent optical properties of rare-earth metals, they have attracted more attention in the field of drug delivery systems [17].

The drug delivery system believes that the carrier with a particle size of $50 \sim 200 \mathrm{~nm}$ can be targeted and retained in the tumor site through the high permeability and long retention effect. $74 \%$ of the fluorescent EU (BTC) nanoparticles synthesized in this study have a particle size of $100 \sim 200 \mathrm{~nm}$. In the meantime, more than $85 \%$ of the nanoparticles have a particle size between 50 and $200 \mathrm{~nm}$, which meets the basic requirements of high permeability and long retention effect [18]. PEG has good compatibility with many organic substances and can improve the surface characteristics of nanoparticles [19], so the rare earth metal-organic framework material nanoparticles modified by PEG have 


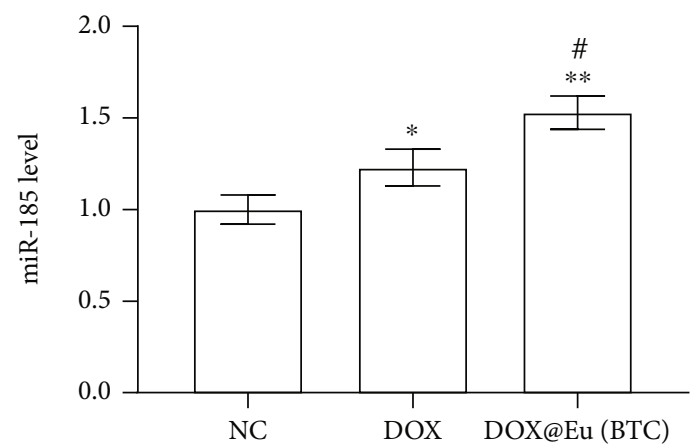

(a)

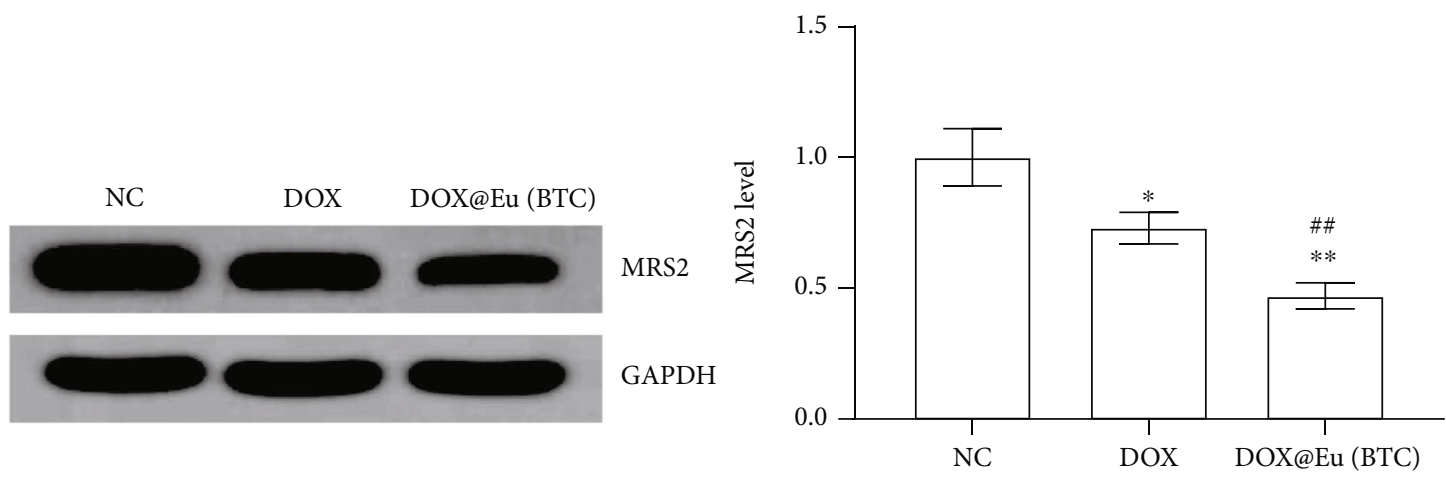

(b)

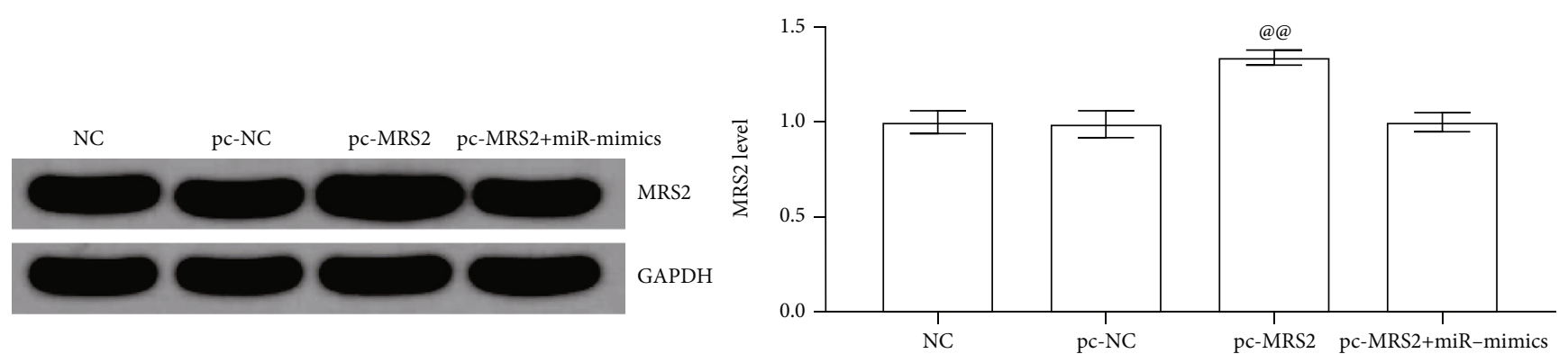

(c)

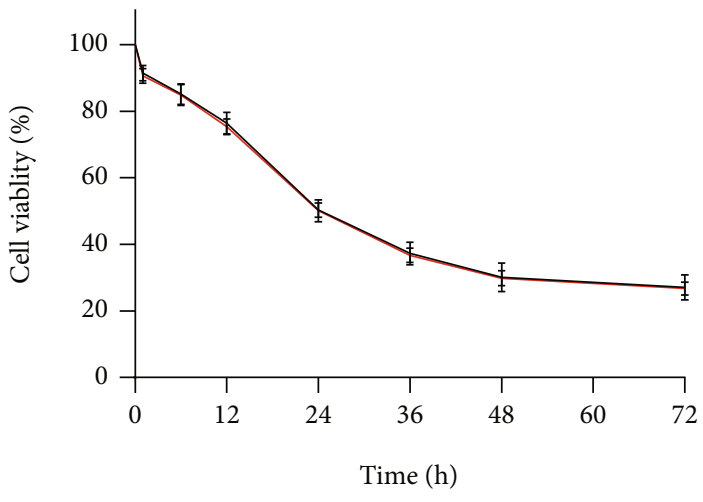

- NC

_ pc-MRS2+miR-mimics

(d)

FIgURe 6: Continued. 

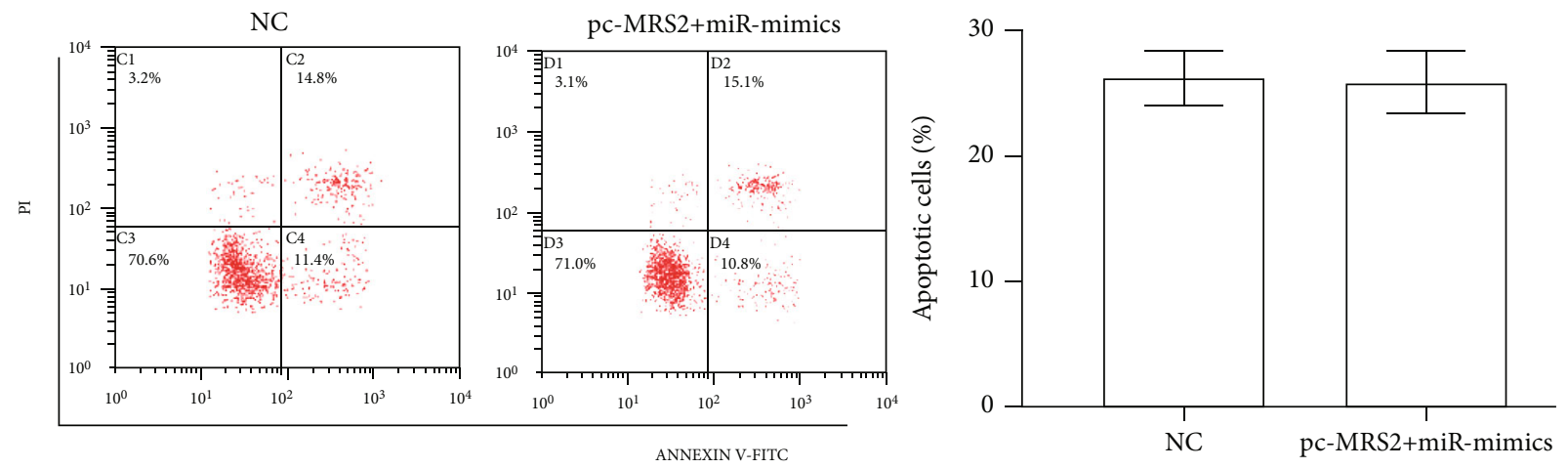

(e)
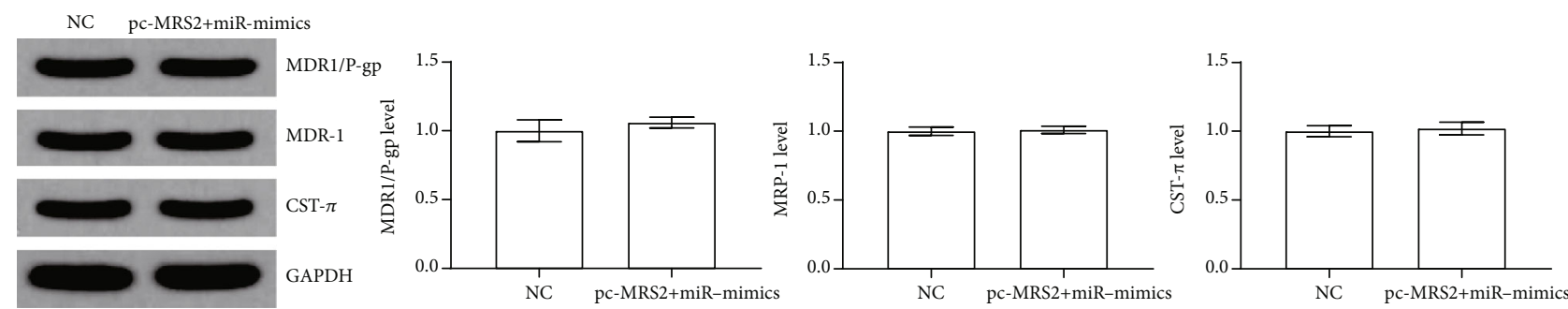

(f)

Figure 6: DOX@Eu (BTC) fluorescent nanoparticles enhance the chemotherapy sensitivity of SGC7901/ADR cells through miR$185 /$ MRS2. ${ }^{*} P<0.05$ and ${ }^{* *} P<0.01$ vs. NC group; ${ }^{\#} P<0.05$ and ${ }^{\#} P<0.01$ vs. DOX group. (a) The expression level of miR-185 in SGC7901/ADR cells. (b, c) The expression level of MRS2 in SGC7901/ADR cells. (d) Comparison of DOX@Eu (BTC) on cell viability SGC7901/ADR cell by different transfection. (e) Comparison of DOX@Eu (BTC) on cell apoptosis rate SGC7901/ADR cell by different transfection. (f) Comparison of DOX@Eu (BTC) on multidrug resistance protein relative expression SGC7901/ADR cell by different transfection.

become a better choice for nano-medicine carriers. Fluorescent EU (BTC) nanoparticles are modified by PEG to form a "molecular brush" on their surface, which improves the biocompatibility and prolongs the circulation time in the body without affecting the pore performance of fluorescent EU (BTC) nanoparticles. The specific surface area test of PEG-modified fluorescent EU (BTC) nanoparticles confirmed the above point of view. DOX is loaded on PEGmodified fluorescent EU (BTC) nanoparticles to obtain fluorescent DOX@Eu (BTC) nanoparticles. The results of laser confocal microscope observation showed that fluorescent DOX@Eu (BTC) nanoparticles are present in the cytoplasm of SGC7901/ADR cells or on the cell membrane, while DOX is fixed in EU (BTC) nanoparticles. Besides, the results of the thermogravimetric analysis showed that the effective drug loading of the nanoparticles was about $29 \%$, which was much higher than the drug loading of traditional nanomedicine [20]. The ability to prevent the drug burst effect in the drug delivery system is an important index to evaluate its performance. Studies have shown that the $\mathrm{pH}$ of tumor tissue is usually between 5 and 6, which is acidic [21]. The in vitro release test results showed that the fluorescent DOX@Eu (BTC) nanoparticles prepared in this study have $\mathrm{pH}$-responsive release performance, were not easy to release in a neutral environment, but can be released quickly in an acidic environment, which will not cause harm to normal tissues, and can ensure the concentration of the drug in the tumor tissue. In summary, the fluorescent DOX@Eu (BTC) nanoparticles prepared in this study can target tumor tissues through high permeability and long retention effect, reduce the release of drugs in normal tissues, which can in turn reduce the side effects of chemotherapy drugs on patients, and enhance the killing effect of chemotherapy drugs on tumor tissues and cells. At the same time, the follow-up cell experiment results also showed that fluorescent DOX@Eu (BTC) nanoparticles have stronger cytotoxicity to SGC7901/ADR cells than free DOX, and enhanced the induction of SGC7901/ADR cell apoptosis. Also, it can effectively inhibit the expression of multidrug resistance protein in SGC7901/ADR cells.

miRNA is a noncoding single-stranded RNA molecule with a length of about 22 nucleotides, which is closely related to the multidrug resistance of tumor cells. Studies have shown that miR-185 is not only closely related to a variety of tumors but also related to the multidrug resistance of tumor cells. Xia et al. demonstrated that transfected miR185 mimics could effectively reverse the multidrug resistance of SGC7901/ADR cells [11]. In this study, it was found that compared with the GES-1 cell line, the expression of miR185 in SGC7901 and SGC7901/ADR cells was significantly reduced, and the expression in SGC7901/ADR cells was lower than that in SGC7901 cells. Transfection of miR-185 mimics can significantly enhance the toxicity of fluorescent DOX@Eu (BTC) nanoparticles to SGC7901/ADR cells, but significantly downregulate the expression of multidrug resistance protein. Human mitochondrial MRS2 protein (MRS2) is a magnesium transporter in the inner mitochondrial 
membrane, responsible for the transportation of magnesium ions $\left(\mathrm{Mg}^{2+}\right)$ in the mitochondria. As one of the more abundant cations in cells, $\mathrm{Mg}^{2+}$ plays a role in cell apoptosis [22]. The homeostasis of $\mathrm{Mg}^{2+}$ in the body is mainly maintained by the expression of magnesium transporters. When the homeostasis of $\mathrm{Mg}^{2+}$ is destroyed, the prevalence of cancer will increase [23]. Studies have shown that the expression of $\mathrm{Mg}^{2+}$ in drug-resistant gastric cancer cell lines is significantly higher than that of nonresistant gastric cancer cell lines [24]. This study found that the expression of MRS2 protein in SGC7901 and SGC7901/ADR cell lines increased significantly, and the expression of MRS2 protein in SGC7901/ADR was significantly higher than that in SGC7901 cells. After the transfection of si-MRS2, the sensitivity of SGC7901/ADR to fluorescent DOX@Eu (BTC) nanoparticles was enhanced, and the inhibitory effect of fluorescent DOX@Eu (BTC) nanoparticles on the expression of multidrug resistance protein in SGC7901/ADR was also enhanced. Also, the bioinformatics prediction website showed that miR-185 has a targeted binding sequence with MRS2. The dual-luciferase reporter gene experiment confirmed that MRS2 was the downstream target gene of miR-185, and miR-185 negatively regulated the expression of MRS2. In summary, the expression level of miR-185 in SGC7901/ADR cells was reduced, but the expression of MRS2 protein in SGC7901/ADR cells was increased. miR-185 and MRS2 proteins are closely related to the multidrug resistance of SGC7901/ADR cells.

Further research found that after fluorescent DOX@Eu (BTC) nanoparticles treated SGC7901/ADR cells, the expression of miR-185 in the cells increased significantly, the expression of MRS2 protein decreased significantly, and the magnitude of the change was more obvious than that of DOX treatment. After transfection of miR-185 mimics and pc-MRS2 at the same time, the expression of MRS2 protein in SGC7901/ADR cells did not change significantly, and simultaneous transfection does not affect the sensitivity of SGC7901/ADR cells to fluorescent DOX@Eu (BTC) nanoparticles. In summary, DOX and fluorescent DOX@Eu (BTC) nanoparticles inhibited the translation of MRS2 protein by upregulating the expression of miR-185, thereby affecting the chemotherapy sensitivity of SGC7901/ADR cells.

The fluorescent DOX@Eu (BTC) nanoparticles constructed in this study have both high-drug loading, $\mathrm{pH}$ sensitive release and fluorescence characteristics. While controlling the slow release of antitumor drugs, it may also have the function of imaging contrast agent. In the future, it has great potential in targeted therapy and imaging applications for the treatment of gastric cancer. However, due to time and experimental conditions and other constraints, this study only explored the effect and mechanism of DOX@Eu (BTC) fluorescent nanoparticles on drug-resistant gastric cancer cells within a certain range. The DOX@Eu (BTC) fluorescent nanoparticles have a large number of carboxyl groups on the surface. The modified carboxyl group combined with the $\mathrm{pH}$-sensitive release function enables it to regulate the distribution of chemotherapeutic drugs in the patient's body, reduce the side effects of chemotherapeutic drugs on the patient, and increase the concentration of the drug at the tumor site. In the follow-up study, we will modify the carboxyl groups on the surface of DOX@Eu (BTC) fluorescent nanoparticles and explore its influence on the distribution of DOX in model animals.

In conclusion, the results of this study indicated that fluorescent DOX@Eu (BTC) nanoparticles can effectively enhance the chemotherapeutic sensitivity of SGC7901/ADR cells to DOX, and the mechanism of action may be achieved by further increasing the expression of miR-185 and inhibiting the expression of MRS2 protein.

\section{Data Availability}

The data used to support the findings of this study are included within the article.

\section{Conflicts of Interest}

The authors declare that there are no conflicts of interest regarding the publication of this paper.

\section{Acknowledgments}

This research was supported by Guiding Project of Municipal Science and Technology Plan in Quzhou City (No. 20172093).

\section{References}

[1] N. Bizzaro, A. Antico, and D. Villalta, "Autoimmunity and gastric cancer," International Journal of Molecular Sciences, vol. 19, no. 2, p. 377, 2018.

[2] R. Zheng, H. Zeng, S. Zhang, and W. Chen, "Estimates of cancer incidence and mortality in China, 2013," Chinese Journal of Cancer, vol. 36, no. 1, p. 66, 2017.

[3] W. H. Zhang, X. H. Song, X. Z. Chen et al., "Characteristics and survival outcomes related to the infra-pyloric lymph node status of gastric cancer patients," World Journal of Surgical Oncology, vol. 16, no. 1, p. 116, 2018.

[4] Q. W. Wang, X. T. Zhang, M. Lu, and L. Shen, "Impact of duration of adjuvant chemotherapy in radically resected patients with T4bN1-3M0/TxN3bM0 gastric cancer," World J Gastrointest Oncol, vol. 10, no. 1, pp. 31-39, 2018.

[5] M. Rugge, R. M. Genta, F. Di Mario et al., "Gastric cancer as preventable disease," Clinical Gastroenterology and Hepatology, vol. 15, no. 12, pp. 1833-1843, 2017.

[6] Y. Li, B.-b. Tan, L.-q. Fan, Q. Zhao, Y. Liu, and D. Wang, "Heterogeneity of COX-2 and multidrug resistance between primary tumors and regional lymph node metastases of gastric cancer," Tumori, vol. 98, no. 4, pp. 516-522, 2018.

[7] F. Zhu, Q. Wu, Z. Ni, C. Lei, T. Li, and Y. Shi, "miR-19a/b and $\mathrm{MeCP} 2$ repress reciprocally to regulate multidrug resistance in gastric cancer cells," International Journal of Molecular Medicine, vol. 42, no. 1, pp. 228-236, 2018.

[8] Y. Gu, J. Li, Y. Li et al., "Nanomicelles loaded with doxorubicin and curcumin for alleviating multidrug resistance in lung cancer," International Journal of Nanomedicine, vol. Volume 11, no. 11, pp. 5757-5770, 2016.

[9] M. Li, Y. Li, X. Huang, and X. Lu, "Captopril-polyethyleneimine conjugate modified gold nanoparticles for co-delivery of drug and gene in anti-angiogenesis breast cancer therapy," Journal of Biomaterials Science. Polymer Edition, vol. 26, no. 13, pp. 813-827, 2015. 
[10] J. Zhong, R. K. Kankala, S. B. Wang, and A. Z. Chen, "Recent advances in polymeric nanocomposites of metal-organic frameworks (MOFs)," Polymers (Basel), vol. 11, no. 10, p. 1627, 2019.

[11] D. Xia, X. Li, Q. Niu et al., "MicroRNA-185 suppresses pancreatic cell proliferation by targeting transcriptional coactivator with PDZ-binding motif in pancreatic cancer," Experimental and Therapeutic Medicine, vol. 15, no. 1, pp. 657-666, 2018.

[12] Y. Xiang, N. Ma, D. Wang et al., "MiR-152 and miR-185 cocontribute to ovarian cancer cells cisplatin sensitivity by targeting DNMT1 directly: a novel epigenetic therapy independent of decitabine," Oncogene, vol. 33, no. 3, pp. 378-386, 2014.

[13] B. Tan, Y. Li, Q. Zhao, L. Fan, and D. Wang, "ZNF139 increases multidrug resistance in gastric cancer cells by inhibiting miR-185," Bioscience Reports, vol. 38, no. 5, article BSR20181023, 2018.

[14] J. Shi, Y. Su, and Z. Zhang, "A nanoliposome-based photoactivable drug delivery system for enhanced cancer therapy and overcoming treatment resistance," International Journal of Nanomedicine, vol. 14, no. 5, pp. 1840-1841, 2018.

[15] B. Pelaz, C. Alexiou, R. A. Alvarez-Puebla et al., "Diverse applications of nanomedicine," ACS Nano, vol. 11, no. 3, pp. 23132381, 2017.

[16] L. He, Y. Liu, J. Lau et al., "Recent progress in nanoscale metalorganic frameworks for drug release and cancer therapy," Nanomedicine (London, England), vol. 14, no. 10, pp. 1343-1365, 2019.

[17] D. Wang, C. Zhao, G. Gao, L. Xu, G. Wang, and P. Zhu, "Multifunctional NaLnF4@MOF-Ln nanocomposites with dualmode luminescence for drug delivery and cell imaging," Nanomaterials (Basel), vol. 9, no. 9, p. 1274, 2019.

[18] M. Sang, R. Luo, Y. Bai et al., "Mitochondrial membrane anchored photosensitive nano-device for lipid hydroperoxides burst and inducing ferroptosis to surmount therapy-resistant cancer," Theranostics, vol. 9, no. 21, pp. 6209-6223, 2019.

[19] I. Abánades Lázaro, S. Haddad, J. M. Rodrigo-Muñoz et al., "Mechanistic investigation into the selective anticancer cytotoxicity and immune system response of surface-functionalized, dichloroacetate-loaded, UiO-66 nanoparticles," ACS Applied Materials \& Interfaces, vol. 10, no. 6, pp. 5255-5268, 2018.

[20] J. M. Lim, T. Cai, S. Mandaric et al., "Drug loading augmentation in polymeric nanoparticles using a coaxial turbulent jet mixer: Yong investigator perspective," Journal of Colloid and Interface Science, vol. 538, pp. 45-50, 2019.

[21] Y. X. Zhang, Y. Y. Zhao, J. Shen et al., "Nanoenabled modulation of acidic tumor microenvironment reverses anergy of infiltrating $\mathrm{T}$ cells and potentiates anti-PD-1 therapy," Nano Letters, vol. 19, no. 5, pp. 2774-2783, 2019.

[22] L. Merolle, G. Sponder, A. Sargenti et al., "Overexpression of the mitochondrial $\mathrm{Mg}$ channel MRS2 increases total cellular $\mathrm{Mg}$ concentration and influences sensitivity to apoptosis," Metallomics, vol. 10, no. 7, pp. 917-928, 2018.

[23] X. Zhu, M. J. Shrubsole, R. M. Ness et al., "Calcium/magnesium intake ratio, but not magnesium intake, interacts with genetic polymorphism in relation to colorectal neoplasia in a two-phase study," Molecular Carcinogenesis, vol. 55, no. 10, pp. 1449-1457, 2016.

[24] Y. Chen, X. Wei, P. Yan et al., "Human mitochondrial Mrs 2 protein promotes multidrug resistance in gastric cancer cells by regulating $\mathrm{p} 27$, cyclin $\mathrm{D} 1$ expression and cytochrome $\mathrm{C}$ release," Cancer Biology \& Therapy, vol. 8, no. 7, pp. 607614, 2014. 